\title{
Interdisciplinaridade na Matemática através da Aprendizagem Significativa
}

\author{
Interdisciplinarity in Mathematics through Meaningful Learning \\ Interdisciplinariedad en Matemáticas a través del Aprendizaje Significativo
}

Recebido: 15/07/2021 | Revisado: 19/07/2021 | Aceito: 26/07/2021 | Publicado: 01/08/2021

\author{
Ana Paula Passos \\ ORCID: https://orcid.org/0000-0002-3431-0416 \\ Universidade Federal do Amazonas, Brasil \\ E-mail: planetacomponentes@ hotmail.com \\ Yuri Expósito Nicot \\ ORCID https://orcid.org/0000-0002-7114-0073 \\ Universidade Federal do Amazonas, Brasil \\ E-mail: yexposito@yahoo.es
}

\begin{abstract}
Resumo
O artigo apresenta uma síntese da pesquisa realizada em 2019 como Trabalho de Conclusão para a obtenção do título de Mestre em Ensino de Ciências e Matemática. A referida pesquisa tem como objetivo constatar que a postura interdisciplinar no Processo de Ensino e Aprendizagem em Matemática no Ensino Médio favorece a assimilação e contextualização do conteúdo Função Quadrática, tendo como base a Teoria da Aprendizagem Significativa de Ausubel e as concepções de Interdisciplinaridade de Hilton Japiassu e Ivani Fazenda. Buscou-se desenvolver a interdisciplinaridade a partir do conteúdo Função Quadrática com outras áreas do conhecimento, destacando a aplicabilidade da aprendizagem interdisciplinar na disciplina de Física através da Resolução de Problemas. Realizouse um estudo de caso de abordagem qualitativa considerando uma amostra de trinta alunos do ensino médio regular em uma escola estadual localizada na cidade de Manaus/AM. Em relação aos instrumentos utilizados para coleta de dados, citam-se: questionários, entrevistas semiestruturadas e observação participante. Os resultados mostraram as dificuldades de se implementar a prática interdisciplinar no dia a dia pedagógico, devido a fatores como: dificuldades de inter-relação entre os conteúdos, falta de apoio pedagógico, entre outros.
\end{abstract}

Palavras-chave: Interdisciplinaridade; Matemática; Aprendizagem significativa; Ensino.

\begin{abstract}
The article presents a summary of the research conducted in 2019 as a Final Work for obtaining the title of Master in Science and Mathematics Teaching. This research aims to verify that the interdisciplinary stance in the Teaching and Learning Process in Mathematics in High School favors the assimilation and contextualization of the Square Function content, based on Ausubel's Theory of Significant Learning and the conceptions of Interdisciplinarity of Hilton Japiassu and Ivani Fazenda. It sought to develop interdisciplinarity from the Squared Function content with other areas of knowledge, highlighting the applicability of interdisciplinary learning in Physics through Problem Solving. A qualitative case study was carried out considering a sample of thirty regular high school students in a state school located in the city of Manaus/AM. The instruments used for data collection were: questionnaires, semi-structured interviews and participant observation. The results showed the difficulties of implementing the interdisciplinary practice in the daily pedagogical routine, due to factors such as: difficulties of inter-relationship between the contents, lack of pedagogical support, among others.
\end{abstract}

Keywords: Interdisciplinarity; Mathematics; Meaningful learning; Teaching.

\section{Resumen}

El artículo presenta un resumen de la investigación realizada en 2019 como Trabajo Final para la obtención del título de Magisterio en Ciencias y Matemáticas. Esta investigación pretende verificar que la postura interdisciplinaria en el Proceso de Enseñanza y Aprendizaje de la Matemática en la Enseñanza Media favorece la asimilación y contextualización del contenido de la Función Cuadrada, con base en la Teoría del Aprendizaje Significativo de Ausubel y las concepciones de Interdisciplinariedad de Hilton Japiassu e Ivani Fazenda. Se buscó desarrollar la interdisciplinariedad a partir del contenido de la Función Cuadrada con otras áreas del conocimiento, destacando la aplicabilidad del aprendizaje interdisciplinario en la disciplina de la Física a través de la Resolución de Problemas. Se realizó un estudio de caso de enfoque cualitativo considerando una muestra de treinta estudiantes de secundaria regular en una escuela estatal ubicada en la ciudad de Manaus/AM. En cuanto a los instrumentos utilizados para la recogida de datos, se mencionan: cuestionarios, entrevistas semiestructuradas y observación participante. Los resultados mostraron las dificultades de implementar la práctica interdisciplinaria en la rutina pedagógica diaria, debido a factores como: dificultades de interrelación entre los contenidos, falta de apoyo pedagógico, entre otros.

Palabras clave: Interdisciplinariedad; Matemáticas; Aprendizaje significativo; Enseñanza. 


\section{Introdução}

A Matemática é utilizada em diversas áreas do conhecimento, de maneira que impulsiona o desenvolvimento social, econômico e tecnológico. No entanto, segundo Pontes (2013), ela é apresentada no ambiente escolar de maneira complexa e descontextualizada, isto é, distante do cotidiano do aluno.

Considerando também a prática docente dos autores responsáveis por essa pesquisa, pode-se afirmar que os alunos apresentam dificuldades em associar o conteúdo ministrado em sala de aula com o seu cotidiano. Para permitir a delimitação necessária no estudo dessa situação, optou-se pelo conteúdo matemático Função do Segundo Grau. Esse conteúdo faz parte do currículo da Educação Básica desde o nono ano do Ensino Fundamental. Apesar disso, os alunos chegam ao Ensino Médio apresentando dificuldades em fazer as devidas associações matemáticas visando à resolução de problemas mesmo em outras disciplinas.

De acordo com esse contexto, determinou-se o seguinte problema científico: "Como o Processo de Ensino e Aprendizagem, partindo de uma abordagem interdisciplinar, permite que os alunos apliquem seus conhecimentos matemáticos sobre Função Quadrática em outras áreas do conhecimento?”. Diante dessa inquietação, realizou-se um trabalho interdisciplinar como estratégia e recurso para auxiliar o ensino e facilitar a aprendizagem do aluno. É importante ressaltar que o conteúdo matemático Função Quadrática serve como “instrumento” para auxiliar na contextualização de problemas vividos no cotidiano do aluno através da estratégia de resoluções de problemas.

Esse estudo baseou-se nas orientações da Base Nacional Comum Curricular (BNCC), sob o foco da Interdisciplinaridade. Destacaram-se ainda as concepções de Japiassu (1994) e Fazenda (1999), que entendem a interdisciplinaridade como a síntese das atitudes de reciprocidade no diálogo, atitude de humildade diante das limitações, atitude de desafio perante o novo e atitude de envolvimento, comprometimento e responsabilidade na relação entre as disciplinas do currículo escolar.

A pesquisa fundamentou-se também na Teoria da Assimilação de David Ausubel, segundo a qual a aprendizagem não deve estar acessível somente para ser utilizada em situações semelhantes às situações em que se propiciou a construção de novos conhecimentos, mas, também, para transferência em outros contextos e realidades, Ausubel et al. (1980).

Ao longo desse artigo, fez-se uma fundamentação teórica sobre o Processo de Ensino e Aprendizagem de Matemática e sua aplicabilidade. Em relação à interdisciplinaridade, pontuou-se sobre suas dificuldades, sua aplicação na aprendizagem significativa e também na disciplina de Matemática. Por fim, descreveu-se a metodologia utilizada no estudo de caso e foi discutida a análise dos resultados obtidos.

\section{Processo de Ensino e Aprendizagem na Matemática e sua Aplicabilidade}

De acordo com Moreno (1993), pode-se definir Processo de Ensino e Aprendizagem como um sistema de interações entre o professor e aluno. Nesse sistema, o processo de ensinar e aprender se entrelaçam, apesar da distinção de seus agentes. O “aprender precedeu o ensinar, ou, em outras palavras, ensinar se diluía na experiência realmente fundante de aprender" Freire (1999, pp. 25-26). Neste processo, o professor atua como mediador entre o aluno e os conteúdos destinados a serem aprendidos.

O Processo de Ensino e Aprendizagem da Matemática, no decorrer do tempo, sempre esteve ligado a diferentes áreas do conhecimento, respondendo a muitas questões, seja na área econômica, administrativa, tecnológica, afetando a todos os tipos de atividades humanas. Entretanto, mesmo fazendo parte do nosso cotidiano na forma de porcentagens, estatísticas, juros, etc., o ensino da Matemática possui uma antipatia que influencia negativamente o rendimento e a aprendizagem dos alunos, nos diferentes níveis de ensino, elevando os índices de reprovação. De acordo com o Sistema de Avaliação da Educação Básica 
(SAEB, 2017), apenas 4,52\% dos estudantes da última série do Ensino Médio alcançaram níveis de aprendizagem classificados como adequados pelo MEC.

Portanto, de acordo com autores como Dante (1998), Bassanezi (1994) e Borin (1996), nos últimos anos novas propostas pedagógicas estão sendo inseridas nas salas de aula. Essas propostas de trabalho pedagógico consideram os processos cognitivos, afetivos, motivacionais e metodológicos. Em resultado disso, surgem concepções de Ensino e Aprendizagem que influenciam todas as áreas do conhecimento. Algumas tendências pedagógicas como resolução de problemas, modelagem matemática, jogos e curiosidades, estão sendo aplicadas com o objetivo de alcançar um ensino comprometido com as transformações sociais e a construção da cidadania.

Além disso, essas novas propostas de trabalho pedagógico buscam o desenvolvimento educacional com a participação ativa do aluno no processo em um contexto de trabalho em grupo; a proposição de uma Matemática significativa para o aluno, baseada no cotidiano; bem como a utilização de recursos específicos e um ambiente que possibilite o desenvolvimento de sequências metodológicas através das quais o aluno construa o seu próprio conhecimento.

\section{Interdisciplinaridade}

O movimento defensor da interdisciplinaridade no ambiente escolar surgiu na Europa, mais precisamente na França e na Itália da década de 1960. Segundo Fazenda (1999, p.16), no Brasil, a interdisciplinaridade chegou como um modismo da época, com várias distorções. A primeira preocupação em relação a esse novo termo era a de conceituá-lo, pois a palavra era considerada como difícil de pronunciar e de escrever. Além disso, a ideia de um ensino interdisciplinar trazia a concepção, no julgar de muitos, da "necessidade da construção de um novo paradigma de ciência, de conhecimento, e a elaboração de um novo projeto de educação, de escola e de vida".

$\mathrm{Na}$ verdade, a prática interdisciplinar surgiu para superar a fragmentação do conhecimento, através do diálogo entre as diversas disciplinas científicas e curriculares, uma vez que o saber precisa ser universal. Desse modo, a interdisciplinaridade surge como a prática pedagógica capaz de proporcionar um novo nível de comunicação entre os diversos componentes curriculares. Para isto, é necessário superar o ensino tradicional “.... baseado na transmissão verbal de conceitos e memorização mecânica com uma visão simplificada do ensino, do professor e de sua informação” Langhi e Nardi (2012, p. 41).

De acordo com Japiassu (1994, p.1), “o saber em migalhas revela uma inteligência esfacelada. O desenvolvimento da especialização dividiu ao infinito o território do saber. Cada especialista ocupou, como proprietário privado, seu minifúndio de saber, onde passa a exercer ... seu minipoder".

Conforme Fazenda (1991, p. 39), a interdisciplinaridade é "uma relação de reciprocidade, de mutualidade, que pressupõe uma atitude diferente a ser assumida frente ao problema de conhecimento, ou seja, é a substituição de uma concepção fragmentária para unitária do ser humano", ou seja, da capacidade de estabelecer relações entre os diferentes conhecimentos, em um mundo de relações. O conhecimento é dinâmico, portanto, faz-se necessário estabelecer relações dialéticas no emaranhado sistema de conexões cognitivas. Ainda conforme Fazenda (2003, p.41), "se o conhecimento fosse absoluto, a educação poderia constituir-se numa mera transmissão e memorização de conteúdo. Mas, como é dinâmico, há necessidade da crítica, do diálogo, da comunicação, da interdisciplinaridade".

Para (Heckhausen, 1972, citado em Fazenda, 1991, p.30), a interdisciplinaridade se subdivide em:

- Interdisciplinaridade Heterogênea: trata-se da união dos conteúdos de diversas disciplinas que visa a uma formação ampla e geral;

- Pseudo-interdisciplinaridade: utiliza-se de uma estrutura de união, uma espécie de "metadisciplina", geralmente um modelo teórico que é aplicado para ser trabalhado em disciplinas distintas. Porém, para Japiassu (1976), o emprego 
de instrumentos comuns não é suficiente para conduzir a um empreendimento interdisciplinar. Esse autor caracteriza a "pseudo-interdisciplinaridade" como falso interdisciplinar;

- Interdisciplinaridade Auxiliar: de acordo com Carlo (1995), consiste no fato de uma disciplina tomar de outra empréstimo de seus métodos ou de seus procedimentos. A interdisciplinaridade auxiliar tem como um dos objetivos a socialização dos saberes para possibilitar novas visões referentes a um assunto específico em benefício de outro.

- Interdisciplinaridade Compósita: trata-se da reunião de conhecimentos diversos para resolver determinados problemas, encontrar soluções técnicas. Ou seja, resolver os grandes e complexos problemas da sociedade contemporânea: fome, poluição, guerra, entre outros.

Interdisciplinaridade Unificadora: Promove tanto a integração teórica com os métodos correspondentes das diversas disciplinas em interação. Como a Biofísica, que possui fenômenos os quais não seriam entendidos somente a partir da Física ou da Biologia. Para Japiassu (1976), a interdisciplinaridade unificadora é a forma legítima da Interdisciplinaridade, embora reconheça que somente por meio da pesquisa científica essa forma de trabalho pedagógico terá a sua devida implementação.

É evidente que nenhuma disciplina do currículo escolar não pode ser apresentada de uma forma isolada. Segundo (Fazenda 2002, citado em Bonatto et al, 2012, p. 3), "o pensar interdisciplinar parte da premissa de que nenhuma forma de conhecimento é em si mesma racional. Tenta, pois, o diálogo com outras formas de conhecimento, deixando-se interpenetrar por elas". Salienta-se que a interdisciplinaridade não tem como função criar uma nova disciplina, mas sim utilizar os conhecimentos de várias disciplinas para resolver um problema ou compreender determinados fenômenos por diferentes pontos de vista, tudo conforme as diversas situações do cotidiano.

Dessa forma, o ensino fragmentado precisa ceder lugar ao trabalho pedagógico interdisciplinar, segundo Japiassu, (1976, p.15):

O objetivo utópico da prática pedagógica interdisciplinar é a unidade do saber e se amplia quando se reconhece que a Interdisciplinaridade não é algo que se ensine ou que se aprenda, mas algo pelo qual se vive. Sim, a interdisciplinaridade é fundamentalmente uma atitude de espírito. Atitude feita de curiosidade, de abertura, de sentido de aventura, de intuição das relações existentes entre as coisas e que escapam à observação comum.

Fazenda (1998, p.99) questiona a reformulação da educação através da prática interdisciplinar. Como se a solução estivesse "na recuperação da ideia primeira da cultura (formação do homem total), no papel da escola (formação do homem inserido na sua realidade) e no papel do homem (agente de mudanças no mundo)". Também indaga a graduação dos futuros professores, pois acredita que, a partir de uma formação interdisciplinar dos professores, será possível exceder o ensino fragmentado na educação escolar disciplinar. O professor precisa aprender a utilizar outros conhecimentos que não fazem parte do ambiente educativo no qual atua.

No espaço escolar e acadêmico, organizados em disciplinas, a prática interdisciplinar refere-se à ação que parte de uma disciplina, mas utiliza de conceitos ou instrumentos de outras para tratar das questões previstas em seus objetivos. O professor que atua numa perspectiva interdisciplinar é aquele que domina o conteúdo de sua área e recorre a outras disciplinas para explorar plenamente os temas de que está tratando. Cordiolli (2002, p. 19).

A Interdisciplinaridade acontece quando um tema é explorado através de conceitos e instrumentos de outra disciplina. Logo, não é uma prática que exija a reunião de mais de um professor. Em vez disso, o comportamento interdisciplinar exige que o professor ou professora aplique em seu contexto curricular diferentes formas de atuação pedagógica. Fazenda (1994) ressalta que o professor precisa ter uma atitude interdisciplinar, ou seja, necessita ser compromissado para com a aprendizagem 
de seus alunos, buscando constantemente utilizar novas técnicas e procedimentos de ensino e sendo hábil no ato de conhecer e de pesquisar.

A Interdisciplinaridade de forma nenhuma nega a individualidade das disciplinas. Seu intuito é favorecer a inclusão da realidade do aluno dentro do processo de ensino e aprendizagem, levando-o a ser protagonista da própria história dentro de seu contexto social. Portanto, a BNCC traz várias recomendações para os professores com vistas ao trabalho pedagógico de forma interdisciplinar. Conforme o próprio documento, "a BNCC propõe a superação da fragmentação radicalmente disciplinar do conhecimento" Brasil (2017, p.15). Embora haja a recomenção, não se estabelecem propostas de como se trabalhar a interdisciplinaridade no âmbito do ensino público. Essa falta de parâmetros definidos nos documentos norteadores da educação pública visando a uma educação interdisciplinar é uma carga a mais na demanda de responsabilidades dos professores.

É importante, desse modo, estabelecer de forma clara o que é uma atitude ou um comportamento interdiscilipnar. De acordo Fazenda (2013), o termo interdisciplinaridade apresenta inúmeros conceitos e entendimentos, podendo ser interpretado de maneira equivocada como sinônimo de multidisciplinaridade, pluridisciplinaridade e transdisciplinaridade. De uma forma geral, todos esses conceitos refletem práticas pedagógicas que contribuem para a relação existente entre as disciplinas do currículo escolar.

Para Fazenda (2011), a Disciplinaridade consiste na formação do processo de ensino através de disciplinas com conhecimentos especializados, trazendo fragmentos da realidade. Verifica-se esse processo curricular em muitas escolas. Seu currículo escolar é organizado de uma forma que cada disciplina fica restrita dentro do seu próprio arcabouço de saber.

Quanto à Multidisciplinaridade, Fazenda (2011, p. 27) destaca que se refere à "justaposição de disciplinas diversas desprovidas de relação aparente entre elas". Isto é, não existe elo entre as disciplinas, pois o conhecimento informado é de cada matéria, não existindo integração entre elas. Essa prática pedagógica não é considerada eficaz, devido à falta da relação entre os diversos conhecimentos.

A Pluridisciplinaridade, por sua vez, é a "justaposição de disciplinas mais ou menos vizinhas nos domínios do conhecimento" Fazenda (2011, p.27). Assim, consiste em uma reunião de várias disciplinas que se relacionam entre si, devido à existência de uma relação entre as suas diversas áreas de conhecimento. No entanto, cada área de saber procura nessa relação esclarecer melhor o conhecimento específico de sua própria área.

Para Japiassu (1976), a Transdisciplinaridade busca conhecer qual a importância de cada ligação no processo pedagógico e o seu papel na resolução do problema, isto é, busca a integração de várias especialidades para a compreensão do mundo.

De acordo com Matos (2003, p.45), na corrente interdisciplinar de Fazenda:

A construção da pesquisa em interdisciplinaridade ... obriga a transformação do pesquisador de mero agente, operário da pesquisa, em livre-pensador e formador de opinião, dado que este se torna o "dono" de seu próprio método. Ele não tem a obrigação de coletar dados, como de fazer parte destes dados. O objeto de pesquisa torna-se seu próprio pesquisador.

São vários os grupos de pesquisa em todo o mundo que vêm discutindo e promovendo a superação das limitações do conhecimento fragmentado a partir do processo interdisciplinar. Através da interdisciplinaridade, permite-se não somente o diálogo entre as disciplinas, mas, principalmente, a conscientização de que os saberes não são estanques e que sua dialética interdisciplinar contribui para um ensino integral, humano e cidadão.

\subsection{Dificuldades para implantação de práticas interdisciplinares}

Os professores nos dias atuais ainda encontram muitas dificuldades para integrar as disciplinas e contextualizar os 
conteúdos. Isso se deve principalmente à questão da formação docente em faculdades e universidades com uma visão positivista e fragmentada do conhecimento. Isto é, a fragmentação do conhecimento científico tem trazido prejuízo para a educação oferecida na Educação Básica. A formação docente centralizada em um currículo fragmentado compromete a relação entre o conhecimento curricular e o cotidiano, impedindo a ocorrência da aprendizagem significativa.

Os cursos de formação docente precisam rever, refazer e reconstruir suas grades curriculares para derrubar os muros do conhecimento fragmentado. Para Fazenda (1991, p.18), "há que se transformar a sala de aula dos cursos de graduação em locais de pesquisa", estabelecendo uma integração com os conhecimentos trazidos pelos alunos, através do diálogo, preparando-os para serem protagonistas da formação do seu conhecimento.

Segundo Bonatto et al. (2012, p. 5), "no mundo atual, moderno e informativo, o professor já não é mais o provedor de conhecimento; agora ele atua como mediador da aprendizagem". Isso significa que o professor deverá ser capaz de inovar, variar suas técnicas de ensinar, buscar qualidade e não se deter em quantidades de conteúdo, tendo bom relacionamento com os alunos e interagir de maneira positiva. $\mathrm{O}$ professor deve preparar seus alunos para conviver em sociedade, valorizando sempre as questões sociais com dignidade, caráter, bondade e honestidade.

Assim, a interdisciplinaridade é uma prática pedagógica onde há interação entre uma, duas ou mais disciplinas. Essa interação pode ocorrer através de uma simples comunicação de ideias ou através da integração recíproca de finalidades, objetivos, conceitos, conteúdos e metodologias das disciplinas envolvidas. No entanto, quando se trata da implementação da interdisciplinaridade no ambiente escolar, muitos são os desafios encontrados, principalmente no que se refere à integração entre as disciplinas e professores.

Segundo Santomé (1998, p.253):

Planejar, desenvolver e fazer um acompanhamento contínuo da unidade didática pressupõe uma figura docente reflexiva, com uma bagagem cultural e pedagógica importante para poder organizar um ambiente e um clima de aprendizagem coerentes com a filosofia subjacente a este tipo de proposta curricular.

Nota-se que, para que o comportamento pedagógico interdisciplinar ocorra, os professores precisam de uma postura pedagógica diferenciada. Para a realização de um Projeto Pedagógico Interdisciplinar, é necessário que os professores sejam qualificados e comprometidos com o princípio científico. Fazenda (1991, p.83) comenta que "numa sala de aula interdisciplinar, todos percebem e se tornam parceiros. Parceiros de quê? Da produção de um conhecimento para uma escola melhor, produtora de homens felizes".

Embora sejam muitas as dificuldades para ministrar uma aula interdisciplinar, muitas das soluções estão nos próprios docentes. Eles precisam buscar maneiras de motivar e verificar o que pode vir a prejudicar a construção do conhecimento dos alunos. Para isso, é fundamental que o docente domine o conteúdo que irá ministrar, disponha de uma visão muito mais ampla de sua disciplina e seja capaz de fazer diferentes associações entre os conteúdos. De acordo com Gil-Perez (2006, p.70):

Os cursos deveriam enfatizar os conteúdos que o professor teria que ensinar, proporcionar uma sólida compreensão dos conceitos fundamentais; familiarizar o professor com o processo de raciocínio que subjaz à construção dos conhecimentos, ajudar os futuros professores a expressar seu pensamento com clareza; permitir conhecer as dificuldades previsíveis que os alunos encontrarão ao estudar tais matérias, etc.

Nesse mesmo sentido, Rivarossa de Polop (1999) descreve os principais obstáculos a serem vencidos para a implementação da Interdisciplinaridade nas salas de aula. São eles: a) os futuros professores não são preparados na universidade para trabalhar interdisciplinarmente; b) distância de linguagem, perspectivas e métodos entre as disciplinas; c) ausência de espaços e tempos nas instituições para refletir, avaliar e implementar inovações educativas. 
A interação do professor com o aluno é um dos maiores passos para a implementação da prática interdisciplinar. Somente essa interação permitirá determinar as dificuldades do aprendizado no percurso do processo de ensino e aprendizagem. O esforço de integrar todo o conhecimento para um único resultado deve ser, desse modo, a responsabilidade de cada indivíduo envolvido no processo educativo.

\subsection{Interdisciplinaridade aplicada na Aprendizagem Significativa}

Para Moreira (2012, p. 13), a aprendizagem significativa é:

... aquela em que as ideias expressas simbolicamente interagem de maneira substantiva e não-arbitrária com aquilo que o aprendiz já sabe. Substantiva quer dizer não-literal, não ao pé da letra, e não-arbitrária significa que a interação não é com qualquer ideia prévia, mas sim com algum conhecimento especificamente relevante já existente na estrutura cognitiva do sujeito que aprende.

Em outros termos, a aprendizagem significativa traz a possibilidade de integração do conhecimento do cotidiano com o aprendizado escolar do aluno. Na Teoria de Ausubel et al. (1980), a aprendizagem pode ocorrer basicamente de duas maneiras: mecânica e significativa. Esses formatos se diferenciam de acordo com as atividades que o aluno está realizando e os tipo mais comuns de aprendizagem escolar.

$\mathrm{Na}$ aprendizagem mecânica, o conteúdo a ser aprendido não tem ligação com algo conhecido. Isso ocorre quando o aluno decora fórmulas, leis ou conceitos. Ausubel et al. (1980) ressaltam que, para que ocorra uma aprendizagem significativa, os conhecimentos prévios (subsunçores) devem servir de base para um novo significado, ocorrendo várias intervenções e relações entre esses saberes.

Ainda sobre a teória de Ausubel, são duas as condições necessárias para a Aprendizagem Significativa. A primeira condição é que o novo conhecimento a ser aprendido seja potencialmente significativo, ou seja, que, de algum modo, esse conhecimento faça sentido para o aluno. A segunda condição é que o aluno precisa ter disposição para aprender, isto é, o aluno precisa buscar o conhecimento.

Pode-se notar que essas condições se equiparam à lógica da interdisciplinaridade. Conforme Fazenda expressa: “.... a lógica que a interdisciplinaridade imprime é a da invenção, da descoberta, da pesquisa, da produção científica, porém gestada num ato de vontade, num desejo planejado e construído em liberdade” Fazenda (2006, pp. 18-19).

Em qualquer intervenção didática empregada no ambiente escolar, busca-se aperfeiçoar as concepções prévias da estrutura cognitiva. Entretanto, devido à abordagem fragmentada dos temas, conteúdos, entre outros, é necessário analisar o que os alunos entendem sobre um determinado conceito.

O professor deve trabalhar sua prática pedagógica de forma que promova a transformação das novas informações em conhecimentos relevantes. Para que isso ocorra, é necessário investigar o cotidiano dos alunos. Abordar os conhecimentos desse modo implica fazer ligações entre as disciplinas, associando-as aos aspectos históricos, filosóficos e sociais dos conteúdos. Isso faz com que os educandos sejam cada vez mais participativos, com uma postura crítica, reflexiva, comprometidos com a transformação pessoal e, por consequência, com uma percepção diferente em relação aos assuntos escolares do seu dia a dia.

A mediação é fundamental para que ocorra a aprendizagem significativa, pois ela interliga os assuntos, explorando e facilitando o entendimento do mundo e de suas interações. De acordo com Boff et al. (2008), um ensino contextualizado entre disciplinas, refletindo sobre o contexto social e cultural dos saberes, tem como pressuposto uma atitude interdisciplinar, o que, por sua vez, permite um diálogo para melhor compreender um conceito em diversas situações.

Sobre a desconexão entre os conteúdos, Fazenda (1991, p.59) "que se pretende na interdisciplinaridade, não é anular a 
contribuição de cada ciência em particular, mas, apenas, uma atitude que venha impedir que se estabeleça a supremacia de determinada ciência, em detrimento de outros aportes igualmente importantes".

A fragmentação conceitual, onde o assunto é explanado de forma isolada, acaba tornando-o mais complexo e repetitivo, ou seja, um ensino mecânico. Assim, a atitude interdisciplinar do professor the dá a possibilidade de interligar os conceitos e mediar o entendimento do aluno, sem prejudicar as particularidades de cada disciplina.

A aprendizagem significativa, desse modo, busca dinamizar o aprendizado com ações de ensino direcionadas para que os alunos aprofundem os seus conhecimentos. Para isso, as interconexões conceituais entre as disciplinas devem ser realizadas. De acordo com Gasparian (2006), a reflexão do aluno e a consciência de que o conhecimento é uma ferramenta de mudança torna o ensino mais significativo.

\subsection{Interdisciplinaridade e a Matemática}

A Matemática está integrada à vida em sociedade, fazendo-se extremamente presente no dia a dia, sendo um saber que possui um extenso campo de aplicação. Todavia, sua aplicabilidade não é tão evidenciada nas escolas. Dessa maneira, os alunos costumam ter uma falsa ideia de que os conteúdos matemáticos ensinados na escola não passam de um saber formal, desvinculado do mundo prático. Diante disso, surge a importância de se integrar a Matemática a diversas outras áreas de conhecimento e, consequentemente, ao entendimento do conceito de interdisciplinaridade dentro do plano de estudo das escolas.

Frequentemente, os meios de comunicação, a televisão, os meios digital ou impresso informam os resultados oriundos dos sistemas de avaliação realizados pelo Sistema de Avaliação da Educação Básica (SAEB), Exame Nacional do Ensino Médio (ENEM), entre outros. Esses índices educacionais demonstram a ineficácia do ensino, especificamente o de Matemática. Segundo os autores Faria e Guirado (2009), os professores da área da Matemática têm investigado novas metodologias para o desenvolvimento do ensino:

...os matemáticos têm buscado caminhos para a melhoria do ensino da Matemática. Para eles, o ensino da Matemática não está acontecendo como deveria e a responsabilidade disso recai sobre nós professores do ensino fundamental e médio. E a consequência de tudo isso é certa aversão dos alunos pela disciplina. Faria e Guirado (2009, p.5).

Adotar metodologias que procurem contextualizar o ensino na sala de aula com o intuito de levar o estudante a construir e compreender a Matemática e seus procedimentos e que também o auxiliem na formalização de diferentes conceitos é uma alternativa para desmistificar esta disciplina.

A contextualização é o ato de vincular o conhecimento teórico e a sua aplicação aos conhecimentos que os educandos já possuem. Segundo os Parâmetros Curriculares Nacionais (PCN 1998), a contextualização e a interdisciplinaridade permitem a relação entre vários conceitos matemáticos e distintas formas de pensamento matemático. Isso se aplica também aos efeitos dos conhecimentos matemáticos em outros campos de conhecimento. Para exemplificar isso, pode-se citar a importância histórica da Matemática no desenvolvimento da tecnologia humana, o que justifica o percurso didático dessa ciência como disciplina escolar. Portanto, quando a escola trabalha o conhecimento de forma contextualizada, o aluno passa da condição de expectador passivo para um aluno autônomo, capaz de ser construtor de seu conhecimento.

No entanto, quando a BNCC versa sobre a contextualização do conhecimento, o ato de contextualizar é estabelecido como uma competência. $\mathrm{O}$ referido documento declara: 
O desenvolvimento dessa competência específica, que é bastante ampla, pressupõe habilidades que podem favorecer a interpretação e compreensão da realidade pelos estudantes, utilizando conceitos de diferentes campos da Matemática para fazer julgamentos bem fundamentados. Brasil (2017, p. 532).

Em busca de novas metodologias para alavancar a eficácia do ensino de Matemática, na atualidade, algumas tendências pedagógicas são aplicadas em sala de aula. Além disso, procedimentos como resolução de problemas, modelagem Matemática, história da Matemática, jogos e curiosidades, Etnomatemática, nova tecnologias e método de projeto são constantes nas salas de aula de Matemática. O objetivo de todo esse arsenal de tendências e procedimentos pedagógicos é possibilitar uma significativa mudança no processo de ensino e aprendizagem de Matemática, tornando o ensino desse importante componente curricular mais contextualizado e mais integrado a outras disciplinas.

Dar ênfase para a resolução de problemas em diferentes situações do cotidiano do aluno é uma estratégia fundamental para tornar a Matemática prazerosa e significativa, demonstrando para o aluno a importância dessa disciplina no contexto cognitivo das demais disciplinas curriculares.

O conteúdo "Funções" é um exemplo de conteúdo matemático que merece uma contextualização bastante consistente. Isso porque dentro desse assunto há diversas aplicações no cotidiano, sempre relacionadas a grandezas, a valores, a índices, a variações, entre outras situações. Por exemplo, a inflação é uma realidade econômica medida através da função que relaciona os preços atuais com os preços anteriores, dentro de um determinado período. Caso ocorra variação para menos, o fenômeno econômico chama-se deflação. Outro exemplo de contextualização dos conhecimentos matemáticos pode ser o cálculo da receita arrecadada em um transporte público em determinado horário, sabendo-se o fluxo de passageiros.

Seguindo a abordagem interdisciplinar e contextualizada dos conteúdos, utilizou-se nesse estudo o conteúdo matemático Função Quadrática. Pode-se observar a sua aplicabilidade principalmente na representação gráfica (parábola). Em edificações como o Palácio do Alvorada e Ponte Juscelino Kubitschek, localizadas em Brasília, é possível observar arcos (parábolas). Assim, a Matemática está em todos os lugares e nas mais variadas aplicações, mesmo que não essas aplicações não sejam percebidas.

Utilizou-se nessa análise o conteúdo Função Quadrática aplicado em problemas contextualizados das disciplinas de Biologia, Química e Física para responder à questão central dessa pesquisa.

\section{Metodologia}

Foi realizado um estudo de caso, de abordagem qualitativa em uma escola pública localizada no munícipio de Manaus/AM. Utilizou-se uma amostra inicial de vinte e sete (27) alunos do ensino médio regular e quatro (04) professores.

Primeiramente, foi realizada uma pesquisa bibliográfica sobre a aplicabilidade de Função Quadrática em outras áreas do conhecimento. Posteriormente, ocorreu uma conversa para explanar a proposta da pesquisa com os professores. Após o aceite, realizou-se uma entrevista semiestruturada durante a qual se abordou sobre a metodologia, tipo e forma de avaliação, planejamento e as dificuldades de uma prática interdisciplinar.

Os alunos participantes da pesquisa foram convidados a se voluntariar, uma vez que uma das condições para a Aprendizagem Significativa, de acordo com a Teoria de Ausubel, é que o indivíduo precisa querer aprender. Para esses alunos voluntários, foi aplicado um questionário diagnóstico com dez questões para avaliar os conhecimentos prévios referentes aos conceitos de Função Quadrática.

A Teoria de Ausubel propõe que o conhecimento prévio dos alunos seja valorizado. Então, a partir da análise do questionário diagnóstico, os professores elaboraram um plano com duração de cinco (05) aulas que foram ministradas presencialmente no turno vespertino. Nas duas primeiras aulas, realizou-se uma síntese sobre o conteúdo matemático, 
incluindo problemas contextualizados, com objetivo de sanar as dificuldades verificadas nos questionários respondidos pelos alunos. As três aulas seguintes foram interdisciplinares, ministradas com as presenças dos professores de Matemática, de Biologia, de Física e de Química.

Enfim, aplicou-se um questionário final contendo quatro questões contextualizadas referente a cada uma das disciplinas, com o objetivo de averiguar se o método interdisciplinar favoreceu a assimilação do conteúdo Função Quadrática aplicado em outras áreas.

\section{Análise e Resultados}

Todos os instrumentos foram analisados através de Análise de Conteúdo. Na entrevista semiestruturada, destaca-se que todos os quatro professores indicaram ser capazes de realizar um ensino interdisciplinar.

A análise foi feita a partir dos seguintes parâmetros: metodologia, tipo e forma de avaliação, planejamento, disposição e dificuldades ao se desenvolver metodologia interdisciplinar. Pode-se ressaltar os seguintes resultados:

1) Sobre a metodologia, houve divergências entre os professores sobre que prática metodológica seria a melhor dentro do contexto vivenciado. Pode-se destacar a Exposição de Conteúdo, Ensino por Resolução de Problemas e Interdisciplinaridade como as metodologias mais indicadas;

2) Nos tipos e formas de avaliação, três professores relataram que realizam avaliações coletivas através de conversa informal, pois a avaliação individual é uma "chuva de notas baixas". Outro professor diz que faz avaliação individual com consulta ao caderno;

3) Em relação ao planejamento, em unanimidade, os professores mostram maior preocupação em cumprir o conteúdo programático, não mantendo o foco na efetivação do aprendizado. A avaliação foi apontada como parte menos importante do planejamento;

4) Acerca da disposição e dificuldades, os professores apontaram a defasagem dos alunos em relação ao conteúdo, a falta de interação entre os professores, a falta de apoio pedagógico, falta de recursos ou espaço físico adequado, número reduzido de aulas, desinteresse e número excessivo de alunos em sala.

$\mathrm{Na}$ análise do questionário diagnóstico, observou-se a dificuldade que os alunos apresentam em relacionar conceitos, diferenciar graus de função e, principalmente, a dificuldade em assimilar os conteúdos quando são aplicados de uma forma contextualizada. No questionário final, somente quatorze alunos estavam presentes. Essa avaliação foi composta por quatro questões contextualizadas. Essas questões foram resolvidas pelos professores em sala de aula, sendo que nenhum dos alunos conseguiu acertar nenhuma das questões.

Por fim, enumeram-se alguns comportamentos observados em todo o processo que podem ter contribuído para o insucesso da prática interdisciplinar: 1) a imposição de uma mesma metodologia para todos os professores; 2) pouco entrosamento entre os professores; 3) a imposição de um tema para os alunos; 4) a dificuldade apresenta pelos alunos em resolver questões contextualizadas e 5) o desinteresse dos alunos. Constatou-se que os envolvidos desconheciam quase que totalmente as dificuldades de implantação de um modelo interdisciplinar.

\section{Considerações Finais}

Como resultado da pesquisa analisada pelos autores, ao realizar uma avaliação com questões formuladas de maneira contextualizada com a realidade do aluno, verificou-se a dificuldade que o aluno apresenta para assimilar os conteúdos estudados em disciplinas diferentes. Portanto, a falta de um planejamento interdisciplinar, número reduzido de aula, 
desinteresse dos alunos e falta de conhecimento são alguns dos motivos para que a interdisciplinaridade não seja vivenciada no ambiente escolar.

Apesar de não se ter alcançado o resultado esperado, devido alguns comportamentos observados no processo, acredita-se que a Teoria de Ausubel relacionada à interdisciplinaridade é adequada para a aplicação e desenvolvimento dessa metodologia. Da mesma maneira, destaca-se que o planejamento é fundamental, principalmente para o desenvolvimento dos professores, que precisam ficar mais conectados e contextualizados dentro de sua prática pedagógica. Ausubel, sempre deixou clara a importância do conhecimento prévio do aluno. Então, é de extrema importância analisar esse conhecimento para planejar o desenvolvimento do conteúdo programado, de forma que as metodologias pedagógicas possam suprir certas deficiências apresentadas pelo aluno.

Acredito que com o apoio pedagógico, para disponibilizar momentos de planejamento, para que os professores se reúnam, e além disso, espaço apropriado, tipo lousas duplas, material didático e cursos de aperfeiçoamento específico na estratégia interdisciplinar, contribuirá para o resultado satisfatório. Enfim, precisa-se graduar e aperfeiçoar os professores em torno das estratégias interdisciplinares para que ocorra uma mudança significativa na educação. Tudo para que os conteúdos estudados não fiquem somente em sala de aula, mas que o aluno consiga assimilá-los e aplicá-los em seu dia a dia.

\section{Referências}

Ausubel, D. P, Novak, J. D., Hanesian, H. (1980). Psicologia Educacional. Interamericana.

BassanezI, R. (1994). Modeling as a teaching-learning strategy. For the learning of mathematics. 14 (2), 31-35.

Boff, E. T. et al. (2008). Situação de Estudo: Uma possibilidade de Reconstrução de Teorias e Práticas Docentes. In: GaliazzI, M.C. et al (orgs). Aprender em rede na educação em ciências. Ijuí: Ed.Unijuí, p.91-112.

Bonatto, A., Barros, C. R., GemelI, R. A., Lopes, T. B. (2012). Interdisciplinaridade No Ambiente Escolar. http://www.ucs.br/etc/conferencias/index.php/anpedsul/9anpedsul/paper/viewFile/2414/50

Borin, J. (1998). Jogos e Resolução de problemas: uma estratégia para as aulas de matemática. Edições Loyola.

Brasil. (2017). Base Nacional Comum Curricular. http://portal.mec.gov.br.

Carlos, J. G. (1995) Interdisciplinaridade no Ensino Médio: desafios e potencialidade. Vozes.

CordiollI, M. (2002). A relação entre disciplinas em sala de aula: a interdisciplinaridade, a transdisciplinaridade e a multidisciplinaridade. A Casa de Astérion.

Dante, L. R. (1998). Didática da Resolução de Problemas de Matemática. 2. Ática.

Faria, C. A. A. P., Guirado, J. C (2009). A Metodologia da Resolução de Problemas. Universidade do Estado do Paraná-UEM.

Fazenda, I. C. A. (1991). Práticas Interdisciplinares na Escola. 8. Cortez, 147 p.

Fazenda, I. C. A. (1994) Interdisciplinaridade: História, Teoria e Pesquisa. 11. Papirus, 143 p.

Fazenda, I. C. A. (1998). Didática e Interdisciplinaridade. 9(1). 192 p.

Fazenda, I. C. A. (1999). A virtude da força nas práticas interdisciplinares. Papirus, 174 p.

Fazenda, I. C. A. (2003). Interdisciplinaridade: qual o sentido? Editora Paulus.

Fazenda, I. C. A. (2006) Interdisciplinaridade na formação de professores: da teoria à prática. ULBRA, 1.190 p.

Fazenda, I. C. A. (2011). Integração e interdisciplinaridade no ensino brasileiro: efetividade ou ideologia. Edições Loyola.

Fazenda, I. C. A. (2013). Práticas interdisciplinares na escola. (13). Cortez.

Freire, P. (1999). Pedagogia da Autonomia: saberes necessários à prática educativa. (12) Paz e Terra.

Gasparian, M.C.C. (2006). Interdisciplinaridade e as questões da aprendizagem. In: Fazenda, I. Interdisciplinaridade na formação de professores: da teoria à prática. Ed. Ulbra.103-111.

Gil-Pérez, D. (2006). Formação de Professores de Ciências: tendências e inovações. (8) Cortez. 
Research, Society and Development, v. 10, n. 9, e54210918294, 2021

(CC BY 4.0) | ISSN 2525-3409 | DOI: http://dx.doi.org/10.33448/rsd-v10i9.18294

Heckhausen, H. (1991). Disciplina e interdisciplinaridade. In: Fazenda, I., Catarina A., Interdisciplinaridade: Um projeto em parceria. Loyola.

Japiassú, H. (1976). Interdisciplinaridade e patologia do saber. Imago.

Japiassú, H. (1994). A questão da interdisciplinaridade. Seminário Internacional sobre Reestruturação Curricular, promovido pela Secretaria Municipal de Educação de Porto Alegre.

http://smeduquedecaxias.rj.gov.br/nead/Biblioteca/Forma\%C3\%A7\%C3\%A3o\%20Continuada/Artigos\%20Diversos/interdisciplinaridade-japiassu.pdf.

Langhi, R.; Nardi, R. (2012). Educação em Astronomia: repensando a formação de professores. Escrituras.

Matos, R. H. de. (2003). O Sentido da Práxis no Ensino e Pesquisa em Artes Visuais: Uma Investigação Interdisciplinar. http://www4.pucsp.br/gepi/downloads/TESES_CONCLUIDAS/Ricardo_Hage.pdf.

Moreira, M. A. (2010). O que é afinal aprendizagem significativa? Aula Inaugural do Programa de Pós-Graduação em Ensino de Ciências Naturais, Instituto de Física, Universidade Federal do Mato Grosso. http://moreira.if.ufrgs.br/oqueeafinal.pdf.

Moreno, A. (1993). Wittgenstein - Através das Imagens. Editora da Unicamp.

Pontes, E. A. S. (2013). Refletindo a Educação frente aos desafios da contemporaneidade. IFAL.

Rivarossa de Polop, A. (1999). El área de ciencias naturales: concepciones epistemológicas y diálogo pedagógico. Cuartas jornadas nacionales de enseñanza de la biología- Memorias. Córdoba: Asociación de Docentes de Ciências Biológicas de la Argentina. 46- 59.

Saeb. (2017). Relatório SAEB 2017. Instituto Nacional de Estudos e Pesquisas Educacionais Anísio Teiceira. https://download.inep.gov.br/publicacoes/institucionais/avaliacoes_e_exames_da_educacao_basica/relatorio_saeb_2017.pdf>

Santomé, J. T. (1998). Globalização e Interdisciplinaridade: o currículo integrado. Artes Médicas Sul Ltda. 